\title{
RE-CONCEPTUALIZATION OF THE IDEA OF NEIGHBORHOOD IN POST-SOCIALIST BELGRADE
}

\section{A B S T R A C T}

Understanding the concept of collective form is of particular interest for re-conceptualization of the idea of neighborhood in post-socialist Belgrade. After the experiences of the socialist community, Belgrade is facing the issue of social atomization and numerous manifestations of the culture of distrust. These conditions in which the duties towards the others are not recognized for the sake of one's own sustain Thomas Hobbes defines as an issue of the wrong reason. In the region of Serbia the problem of wrong reason has its own history. Its fragments are found in the modern urbanization of the cities in Serbia, at the neighborhood level - shaped by the tension between the power directives and the desire of the ordinary people. According to the principle of reciprocity, based on the criteria of functional orientation, attractiveness and connectivity of group form elements, considering the presence of the culture of distrust, the intention of this article is to initiate discussion on proposed terminology and to reveal the key points for transformation of the dwelling community concept into neihgborhood concept. 


\section{INTRODUCTION}

The phenomenon of neighborhood as the form of co-existence is both cultural and sociological phenomenon, but also micro-geographical and urban phenomenon. The manner in which people synchronized their relation in the space of common existence can be considered and compared depending on the culture and climate, regionally and through the history of settlement systems. Maintaing this social and spatial correspondence this paper examines the idea of neighborhood as the relation of distance - the spatial distancing and social restraint.

Understanding the concept of collective form is of particular interest for reconceptualization of the idea of neighborhood in post-socialist Belgrade. There are two reasons for that: (1) The majority form of housing in Belgrade was originated according to the pattern of collective dwelling; (2) Instead of collective dwelling the term multi-family dwelling is currently in use. The prefix "multi" suggests the quantity, but not also the character of relations between the elements of the dwelling entity.

Collective form denotes the segment of city total space. This term was introduced by Fumihiko Maki and Masato Otaka while facing the intensity of urban tendencies of the sixties. Maki and Otaka distinguish three paradigms of collective forms: compositional form, megaform and group form. In contrast to "compositional form" and "megaform", Fumihiko Maki's "group form" is a more flexible urban organization based on a human scale in which the parts and the whole are mutually independent and connected through various linkages (in Perović, 2009:356). Having in mind that contemporary city is not perceived as totality but as a complexity, this paper investigates collective form as a system. The concept of group form is of relevant for the issue of re-conceptualization of the neighborhood because it is developed from the system of generative elements in space, which Maki and Otaka see in the dynamics of human relationships. The group form can thus develop into the system since the individual space within it is connected in a specific way, which is defined but hidden. Alison and Peter Smithson demonstrate how the elements and the system are reciprocal:

The city as a big house lived in by us all, the sum of individual acts freely undertaken is a fine dream, but one not even fragmentarily possible unless the citizen realizes that it is the way he adds that garage to his house and how he shapes and disciplines himself, his children, his household objects, that shapes the neighborhood; and unless the architect 
relearns his discipline, so it can respond to that sort of realization (Alison Smithson / Peter Smithson, 1965: 112).

For Team 10 the group form and its spaces are prototype elements. They are of prototype character due to the system and the way of being interconnected. The development of the prototypes of the group form is the field of competence of architects in the re-conceptualization of the idea of neighborhood.

In analysis of the structure of the residential environment, Stanko Gakovic postulates four criteria for definition or explanation of spatial entity in residential environment: physical distance; functional orientations; spatial inclusion and territorial encompassment of the dwelling units. Functional orientation of the dwelling units is of particular significance. Based on the position of Suzanne Keller that under certain social condition and similar social values, sharing of the service and sharing the space common path could help in creation of the pleasant social contacts. Gaković warns that the common paths may turn into war paths, in the conditions when these common functions are shared by mutually antagonistic groups. Apart from the activity orientation, Gaković emphasizes territoriality ${ }^{1}$ as another important criterion of dwelling units integration (Gaković, 1991:35). Oscar Newman emphasizes that historically intactness of the family living unit and territorial zone of the cluster of family units has always been given architectural expression (Newman, 1974:51). As the system, functional orientation and territoriality are the key criteria for the re-conceptualization of the collective form; both are the culture and social environments in which the group form is shaped.

\section{FRAGMENTS OF THE CULTURE OF DISTRUST - THE ISSUE OF THE WRONG REASON}

After the experiences of the socialist community, Belgrade is facing the issue of social atomization and numerous manifestations of the culture of distrust. In researches of the social aspects of the urban neighborhood in the post-socialist city $^{2}$, Mina Petrović points out to the low level of civic activism in socially heterogeneous neighborhoods and as regards that issue she sums up the statements of the interviewed experts living in New Belgrade. What standpoint present in general is that the citizens have rather little influence upon those who decide on the investments at the level of neighborhood; that the inhabitants are insufficiently informed on the activities in the neighborhood, on who the acters of this activity are; also, the interviewed persons are not sufficiently informed on the results of the initiated actions either; even though being aware of the 
commercialization and usurpation of the space they are not sure within which competence lies the maintenance and regulation of the use of the public and green areas in their neighborhood (Petrović, 2007). These conditions in which the duties towards the others are not recognized for the sake of one's own sustain Thomas Hobbes defines as an issue of the wrong reason (Hobbes, 2006: 70). In the area of Serbia the problem of wrong reasoning drawing has its own history. Its fragments are found in the modern urbanization of the cities in Serbia, at the neighborhood level - shaped by the tension between the power directives and the desire of the ordinary people.

The first neighborhoods in Serbia formed according to the plan emerged by the decree of the Prince Miloš Obrenović dated 1837. After the departure of the Turks from the territory of Serbia, the Prince Miloš ordered strict ordering of settlements. During the Turkish Empire, the Serbs organized their households at the distance one from another, in the settlements of the dispersed type, in the conditions of continual insecurity and distrust. The Decree on regulation of settlements was implemented, as stated by Maksimovic, in such way that the Prince empowered two soldiers to order in three settlements the construction of the houses for those who will be living in the new settlement one next to another, and those who would oppose this Decree were threatened by torching of villages. The two soldiers guaranteed with their own lives to the Prince the implementation of the Decree (Maksimović, 1938: 64-70). Those were mechanisms for the implementation of the plan of the first neighborhoods in Serbia. Pursuant to the Decree the population, used to physically fortify the borderlines of their own property at the distance from the first neighbor, was forced to live one close to another - in the neighborhood, left to their own customs and beliefs to regulate and determine the terms of the common existence.

Besides the Decree, another fragment of the culture of distrust occurring during the period of socialist self-management is important for understanding the specific aspects of the collective form in Belgrade. By the end of the fifties and at the beginning of the sixties the government implemented the concept of the local community as the administrative unit of the city and mechanism of the socialist model of self-management at the territory of Belgrade. In the wording on regulative rules of the local community, which was in effect throughout entire period of self-management, it was stated that the local community was established. It did not emerge spontaneously, of one's own initiative, but its purpose was studied by the city services, it was the result of the decision of higher administrative instances (the municipality). After the Municipal 
National Board had determined the scope of the dwelling community pursuant to its decision, the debate on the $\mathrm{ta} \mathrm{s} \mathrm{k} \mathrm{s}$ (emphasized in the original document) of the dwelling communities was addressed following which by-law of the dwelling community was passed. It was particularly emphasized that these organizations had the task of meeting the requirements of the community and that they could not function as some new acter in the production process, which by its products could make any influence upon the market and intentions of the Social plan (Progres, 1958). This way any entrepreneurship reasoning of the dwellers has been discouraged, for which reason even today when the dwellers of these settlements have the procedural possibility of controlling the changes in their neighborhood, they do not do so because they doubt the institutions. Fearing the revenge (by the individual groups or actors of changes), the dwellers do not express their opinion on the changes in the neighborhood, not even when their rights and interest have been directly endangered (Petrović: 2007).

These two fragments excavated from the period of pre-socialist and socialist period testify that the modern urbanization of the cities in Serbia was implemented as the directive, by the power - by means of decrees, orders, and not by agreements and contracts made between the citizens. Such practice of formulation and implementation of the plans was accepted by the citizens as a rule imposed from the top, the rule which the individual could not have the influence upon, the adoption of which was not questioned. Even though formally not opposed, the individual does not accept the regulations and thus does not behave with respect and awareness of the other, in accordance with the mutually harmonized rule. In such imposed frameworks the individual implements his own rules and objectives. With the lack of institutional support for harmonization of the individual interests on the restricted territory and without institutionalization of the daily practices, the culture of distrust developed its own mechanisms. In other words, the tradition of living in the community of the dispersed type has moved into the physical framework of the neighborhood.

Today in the shadow of the capital projects in New Belgrade such as the construction of the bridges, shopping malls, business and residential complexes collective form is transforming, dramaticaly in its social and in phisical notion. Considering those changes in New Belgrade residential environment it is necessary to study the possibility for re-conceptualization of the idea of neighborhood. Residential zones in New Belgrade was built not only by the 'gifts' of the government, voluntary local taxes and the labor of the dwellers 
of the dwelling community, but also on the basis of the complex, rational, responsible and systematic approach of the experts. This concept of the new territorial unit is known as the Dwelling community of 5000 people. For reconceptualization of the idea of neighborhood it is necessary to understand the program of the dwelling community from the year 1958 on the basis of which the local communities in New Belgrade were formed (Figure 1.1). The following section represents the program of the dwelling community which was published as illustrated magazine. It was compiled and published by the politicians and experts with the objective of presenting the new way of living in the socialist self-management community and bringing its rules closer to its future dwellers.

\section{Dwelling Community Concept}

The study of the dwelling community concept was a comprehensive approach in the conceptualization of the new settlement unit presented in the illustrated magazine for the economic and public affairs dating 1958, "Dwelling Community"3. In this review, the political discourse was supported by the arguments provided by the experts. The complexity of the approach of that time is seen in the content of the publication: political discourse (ideology of socialist self-management), conceptual and program based explanation of the experts (supported by the institutions ${ }^{4}$ ), illustrations of everyday activities (simulations of the desired relationships and activities in the community) and the reviews of the realized settlements (the results of construction of the settlements in Slovenia, Croatia, Bosnia and Herzegovina and Serbia).

In establishing the system of local communities the dwelling community is perceived as the form of the social management 'in which the initiative of each citizen will be allowed'. The author of the local community concept and the major creator of the Yugoslav version of the workers' self-management was Edvard Kardelj, vicepresident of the Federal Executive Committee. At the session of the Federal People's Assambly, at the Plenary session of the Socialist Alliance of Working People of Yugoslavia (Socijalistički savez radnog naroda Jugoslavije, SSRNJ) and at the Annual Assembly of the Standing Conference of the Cities in 1957, Kardelj presented the objectives of this concept:

With the Dwelling Community we gain an instrument most suitable for assisting the construction of our communal system. Besides the Workers' Councils and the Communes, the Dwelling Community is one of the most distinctive forms of social management, in the sphere of helping families and citizens to satisfy the needs of their everyday life (Kardelj, 1957). 
In the dwelling community, the contribution of each member of the community is assumed - both of the children, the young people, the housewives, the employed and the retired. The desired order in the community has been presented and designed in the illustration of the everyday activities of the family members. The photograph simulates the life in the community. The activities are described as the work which provides the mutual success of both the community and the individual. Community services enable saving in time and energy for the parents to work in the factory, the school children look after the younger children, and in school their success depend only on their work, even for the pre-school children the working day starts with the selection of "the tool' for their play in the day-care center. Working day is organized into working hours - the time for the rest is programmed as the stay in the community. In this plan of the new community nobody ought to be forgotten, everyone works, in the company with other, and for the community.

Dealing with the role of the Dwelling Community for the solution of the problems such as the lack of competence and qualified workers the new local community institutions were planned to mobilize human resources of the community: the unemployed, the children and the old; particular attention is paid to women emancipation. Through establishing homes and pioneer centers, the social care for the old and the children has been institutionalized. As the literacy courses and the courses for acquiring additional qualifications were organized the institutions and services engaging informal knowledge of the unqualified dwelling community members have also been set up (housekeeping services, care for the children and the old).

Finally, all those problems treated in the publication become acutely manifest for new settlements. At the end of the publication, examples of completely new-built settlements were presented: University Quarter Prule (Ljubljana), Rapska (Zagreb) and Grbavica (Sarajevo), Zrenjanin (Serbia). This testifies to the complexity of the plan undertaken by the experts to establish the equal living and working standards on the territory of the entire country, in diverse climatic, geo-morphological and social conditions. This is why the concept published in these publication represent base for re-conceptualisation of collective form in post-socialist cities in the region of the former Yugoslavia.

As construction of communal system in this period of socialist self-management was realized according to the top-down management model the experts had a task which included 'putting things in order within an enclosed entity'. This political command should have been translated into objective scientific 
language. Among this group of articles connected with the achievement of the Dwelling Communites' program, two reports are of capital worth for the concept "The Origin of the Programme of the Dwelling Community" and "The Economic Structure of the Dwelling Community". The authors of the first paper provided a pragmatic reply to the political task: "If not exactly the image of the enclosed dwelling community, then the image on the flexible and as universal organism as possible." The upgrading of the social standard and standardization of the production process is presented by the experts. Therefore the task of "putting things in order" translated into the professional terminology means - to fined out adequate urban parameters and the notions which describe the new unit of territorial cohesion. The new community concept comprised the innovation in terminology as well - the parameters are sought which could connect the density of population and the inner dwelling community functions. At that time, in the region of the former Yugoslavia, faced with the rate of construction, the experts left the system of urban planning methodology based on the traditional composition forms and notions: parcel of land, street, city block and study a more general, more connected and full image of the collective form which could meet the rate of construction and the vision of the new society - Dwelling Community for 5000 people. The intention of the state is to establish the territorial and social cohesions - the unity on the territory of the entire state.

Territoriality of the Dwelling Community Four Diagrams of the Dwelling Community

Territoriality is a term which is first of all linked to the manner in which people use the land, regulate their relationships in space and attribute the meaning to the place. The fundamental principles of the theory of territoriality are: first, the organisation of space by human beings is said to have originated in and can be accounted for by universal, biologically determined impulse in individuals to claim and defend a clearly marked 'territory', from which others will be - at least selectively - excluded; and, second, this principle can be extended to all levels of human grouping (all significant human collectives) will claim and defend a territory in the same way that an individual will (Bill Hillier and Julienne Hanson, 1984:6). Robert David Sack uses the term territoriality as a powerful geographical strategy to controle people and things by controlling area (Sack, 1986:5). Acording to Sack, within the domain of society, territoriality can be a catalyst in the process of change and can be used differently and to as much adventage by a class divided as by egalitarian society, in diverse ways but of equal effect both in the systems of the class difference and social 
equality (Sack, 1986:9). The territoriality of the dwelling community was the strategy of establishing socialist version of self-management. Four diagrams represent the key principles of establishing the territoriality of the dwelling community and the starting point for re-conceptualization of the collective form in New Belgrade.

\section{Diagram 1. The order in the enclosed entity}

In establishing the territoriality of the dwelling community the experts were tasked with 'putting things in order within an enclosed - integrated entity'. 'Integrality' reveals the intention that the dwelling area be defined, boundaries determined, and the relations of the elements within the community provide the image of the stable social structure. The control of the interrelations within the community provides governance over the entire territory. Dwelling community presents an indivisible and unchangeable unit of territory whereas the larger entities emerge by joining several dwelling communities, and not by their individual expansion. This principle provides the consistency of the conditions within the community and phased construction of the settlement (Figure 1.2). The urban plan determines the three zones of diverse standard of living. The first zone marks the entrance into the dwelling community territory, next to the center of the dwelling community. The character of this entrance is typically urban, marked by the group of residential towers with the flats having the most modern conveniences. The second zone is the inner, more quiet and calmer part of the territory - the restful area of blocks and row houses, of small number of stories, with more greenery and greater number of playgrounds. The third zone is marked as the flexible area of the individual houses, of the uniform plots of land, of less modern communal facilities for those who carry out construction by oneself. ${ }^{5}$ The rule that the flat has to be an integral part of the formed, enclosed entity fixes the position of each member of the community in its spatial, economic and social structure and contributes to the stability of the entire system.
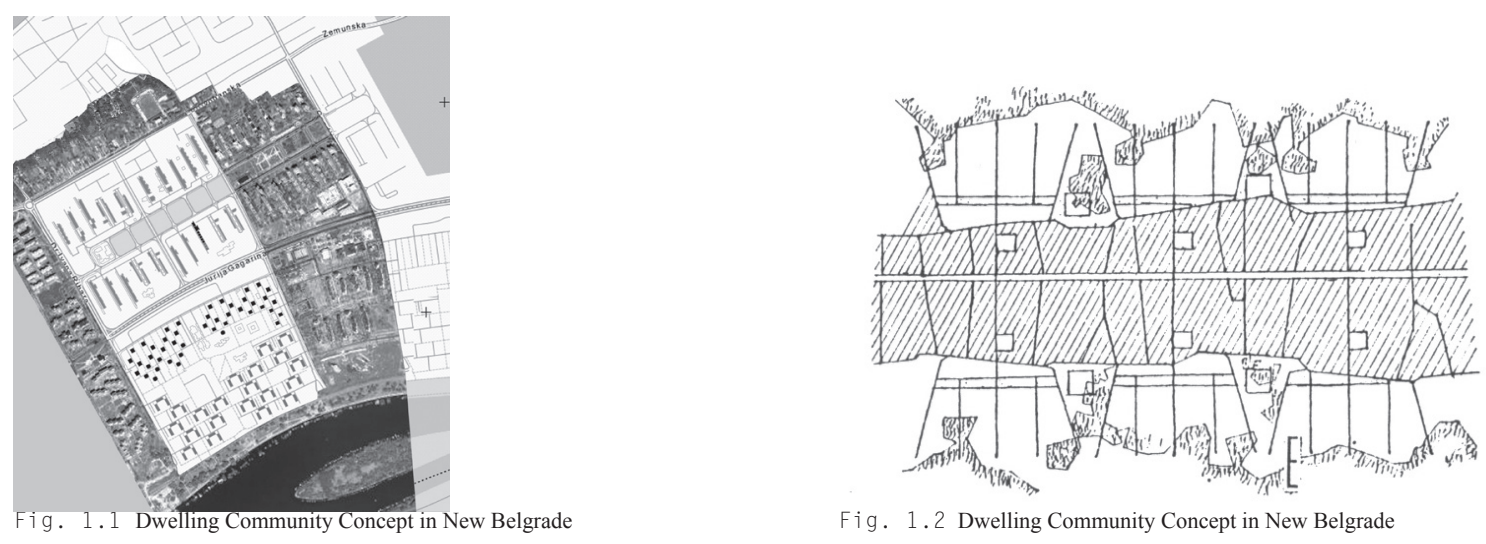

Fig. 1.2 Dwelling Community Concept in New Belgrade 
It is important to point out here that within the community the diversification of the conditions is foreseen, and not the homogenization, as believed in the criticism of the functionalist models. The territory of the dwelling community is divided into three zones of diverse conditions and characters of dwelling. Three types of dwelling entities are represented: the individual houses ( $8 \%$ of the total territory, 5ha, 400 inhabitants), row houses and a three-storey block $(12+65 \%$ of the total territory, 12.25 ha, $600+3250$ inhabitants $)$ and high rises ( $15 \%$ of the total territory, $4.25 \mathrm{ha}, 750$ inhabitants). The number of flats in the individual houses is 56 , in row houses it is 100 , while in three-storey blocks it amounts to 935 whereas in the high rises 541 dwelling units are planned. The dwelling density as per zones are: the zone of individual houses $80 \mathrm{inh} / \mathrm{ha}$, in the row houses zone and in block three-storey houses $250 \mathrm{inh} / \mathrm{ha}$, in the high rises zone the density is $300 \mathrm{inh} / \mathrm{ha}$. The standard foreseen for the flats in the individual houses is $19 \mathrm{sq} . \mathrm{m} / \mathrm{inh}$, in the row houses the standard is $16 \mathrm{sq} . \mathrm{m} / \mathrm{inh}$, in in the blocks 20sq.m./inh, and in high rises 26sq.m/inh.

The manner in which these zones have been integrated into the 'flexible organism' makes this system an open system. The open system comprises its adaptability due to the changes in the social and economic conditions. Such openness of the original conception of the dwelling community offers possibilities for re-conceptualization instead of disputing the collective form.

\section{Diagram 2. Dwelling Community Social Cohesion}

The second diagram displays the distribution of the social institutions within the dwelling community (Figure 2.1): dwelling community administrative center, service and commercial centers, primary school with the gym, pioneer center, home for school children, child day-care, infant nursery. The layout of these spaces depends on the spatial and time related distances between the dwelling unit and the above stated institutions. Therefore, it concerns establishing of the standard of expanded dwelling: maximum distance from the flat to the community commercial, health and public center and to the school is $600 \mathrm{~m}$ (10 minutes), to the commercial and service centers the distance is $160 \mathrm{~m}$ ( 2 minutes), to the child day-care it is $200 \mathrm{~m}$ (3 minutes), and to the infant nursery it is $400 \mathrm{~m}$ ( 5 minutes). The capacity of these institutions is dimensioned according to the projections of the requirements of the dwelling community occupants.

Given that the positions of these services are strategically determined (so that they are accessible to the members of the community and meet the requirements 
of the settlement and that there is no market competition in the settlement) these positions are privileged. Those institutions have monopoly over the requirements of the community of 5000 people, whereas on the other hand they provide the standard of living in the community and their changes are reflected, directly, on the standard of living.

The domain of social standard institutions in the diagram of the activities distribution is presented by circles. Local institutions are in the center of the circle. Territory coverage by the institutions domains provides territorial and administrative control. The services character indicates the space distribution into the service providing and the service receiving. In re-conceptualization, this relation can be perceived in the manner in which Loui Kann thinks of the collective form concept. In which relation are these spaces today and whether it is possible to establish the reciprocity relation between them? How to capitalize the strategic significance of these positions, nowadays, for the benefit of the collective form?

\section{Diagram 3 : Non-transit Area of the Dwelling Community}

The boundary of the dwelling community is determined by the system of roads. All that which stays outside the community is not presented on the dwelling community layout (Figure 2.2) Even though the context is irrelevant for the model representation, in this case deliberately eliminated neighborhood intensifies the self-sufficient, completeness and integrality of the community site and its non-transit character.

One of the characteristics of the territoriality is access control. Access restrictions are not implemented by erecting the fences or walls but by the size and type of public spaces. The boundary is determined by the traffic routes system. In this concept the access is controlled according to the model of two systems of traffic routes (Figure 2.3): the system of bland passage access and orthogonal system of avenues. Instead of the concept of the street as the place of socialization the system of efficient functional network between the place of work and place of dwelling has been applied. The spaces next to the frequent traffic routes are large empty spaces representing a buffer zone between the first dwelling zone and the main avenue. In the buffer zone any activities have been left out, so there is no reason for people to hang around or stay in the street instead inside the community. Emptiness and bigness of the streets sur rounding the community supports the concept of enclose entity. The concept of 
peripheral traffic routes directs the organization of the leisure time activities inside the block so that all requirements can be fulfilled within the boundaries of the dwelling community territory. The blind passage leading inside the residential area and the distances achieved between the traffic routes discourage spontaneous movement and frequenting of the strangers and uninvited persons inside the dwelling community territory. The strangers and accidental passersby have thus been excluded from the territory. For those who are not their dwellers, the new settlements, as New Belgrade was, have been considered as undesired dwelling places during the socialist period. Is this character of inhospitable area in line with government endeavors to suppress the demand in newly constructed housing as the dwellers are permanently bound to the allotted dwelling place, as an predetermined and not the matter of individual preference or personal affinity?

The first deregulation indications are noticed in the areas of dwelling community boundaries and continue through increasingly more expressive transformation. During the postsocialist period shopping centers, traditional blocks of residential buildings and business complexes have been constructed just next to the major avenue. Those new structures blocked well established everyday paths of dwellers and have dramatically altered the original physiognomy of collective form. Actual transformation of buffer zone of the residential zones in New Belgarde should answer the question: which are the designe principles that regulate the boundary in the manner that the inhospitable community area reveals its communicativeness?

\section{Diagram 4. Leisure Time in the Community}

The open spaces within the dwelling community are not freely organized, being more or less successfully maintained green areas, however, they are actually conceptualized as the system of spaces for people to stay within the community, the system of junctions of the collective form. These spaces have been conceived of as the places of staying in the community, outside one's flat which is best illustrated in the activities of the community members. Leisure time is programmed as stay in the dwelling community places: designed children playground between the residential buildings, lawn areas with playgrounds for the ball games, playgrounds annexed to the child daycare, to the Health center, school playgrounds, sports fields and larger green areas in the dwelling community.

As these places for common activities play a significant role in dwelling community territorial and social cohesion, any intervention (physical or 
regulative) relating to dwelling blocks free spaces presents not only the appropriation of the common space and local community ecological resources consumption, but also an essential collective form transformation - change of community interrelations.

These spaces as with its position, size and character provide both the territorial and social dwelling community cohesion. As those spaces should sustain as links in systems each intervention by construction, appropriating of the part of the common space for the individual purposes or change of their modes in use should take into consideration the effects produced upon the commons and demonstrate the care and responsibility for (de)stabilization of relations inside the collective form.

\section{Dwelling Communities in Postsocialist Belgrade - Appropriation of the Commons}

Stanko Gaković, in his research of the residential structure as the factor of the dwelling environment quality provided his criticism of the housing policy which, at that time, under the pretext of promotion of the socially responsible housing, which allowed the action of adaptation of the utilities (storages, laundry rooms, dryer rooms, etc) into dwelling space. Gaković believes that such changes which abolish certain common functional points aggravate the activity structure of the entire residential entity (Gaković, 1991: 34-35). Thereby Gaković hinted at the problems that were soon to follow.

It was already in the first exploitation of the dwelling buildings that the roof terraces and service rooms in the building were adapted into the flats for housekeepers or those whose housing problems are to be solved, but with the time these positions lost their social function - the new dwellers were transferred the right of use of the rooms however, not the obligation of building maintenance.
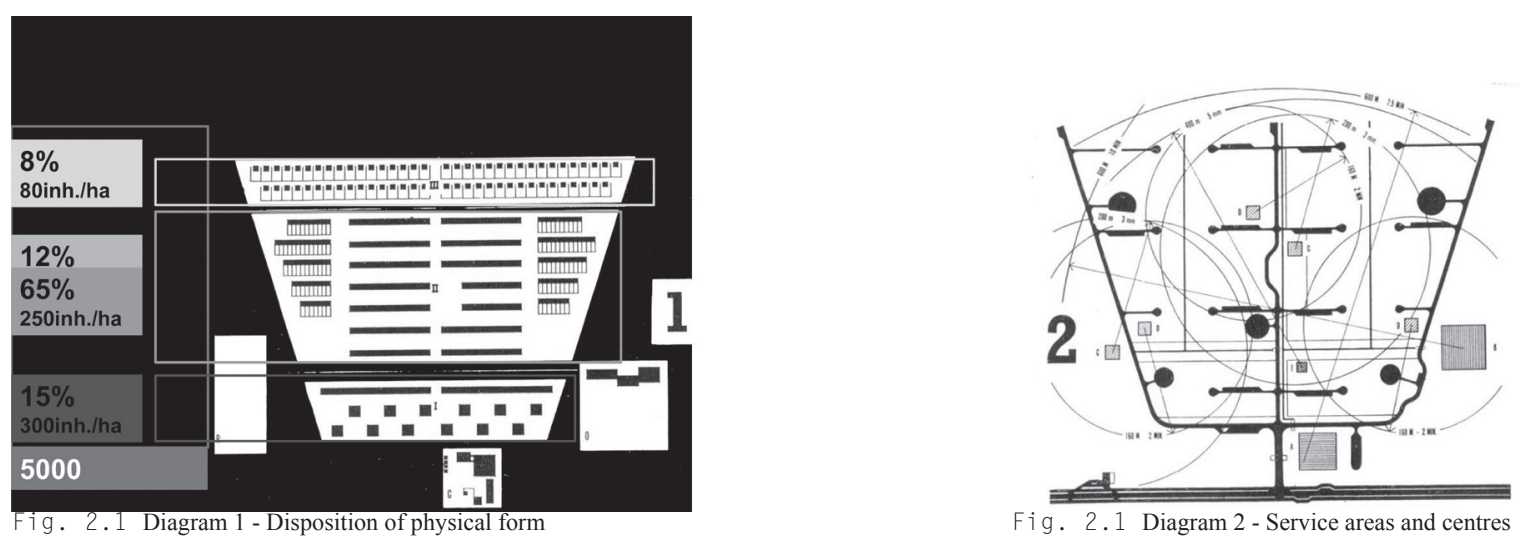
Following adapted flats and all that was common (the entrance, hall, elevator and other rooms) remains within the zone of unregulated relations; therefore it was up to the dwellers to agree on these areas maintenance and use. We often find these areas in the state of neglect or usurpation by the individuals just as the reflection of society atomization, lack of cooperation, unaware of the other as another fragment of the culture of distrust.

The deviations of the dwelling functional orientation is testified also by the statement cited by Petrović on who, in which manner and to what extentdisposes of the common areas in New Belgrade neighborhoods: in a building there was a room for common requirements, covering approximately 70sq.m., the municipality allotted it to a family to use as dwelling space, after a year's period half or portion of that flat was turned into the beverages shop, then into the pub, and then that space was rented by the first user to another one, and that other one turned it into a betting shop (Petrović, 2007). Thus, the individual profit was generated but the social capital of the neighborhood was damaged. ${ }^{6}$

The examples of such privatization of social capital in the area of collective form are numerous. By privatization of the C-market at the city-level, in all local communities there emerged a private company which took the position of the central marketplaces which used to supply the entire dwelling community. The new owner thereby makes the profit not based on the capacities but based on the strategic position in the city and within the dwelling community. The habits of the consumers to get their provisions at that place, the infrastructure level of equipment and traffic meet both the capacity and the type of supplying, and so the new owner 'quietly' moved into the community and took the key position in supplying it. The shelters, also, have the strategic position (good connections for efficient population evacuation). The shelter buildings in New Belgrade were covered with green hills for children to play, and in the nineties
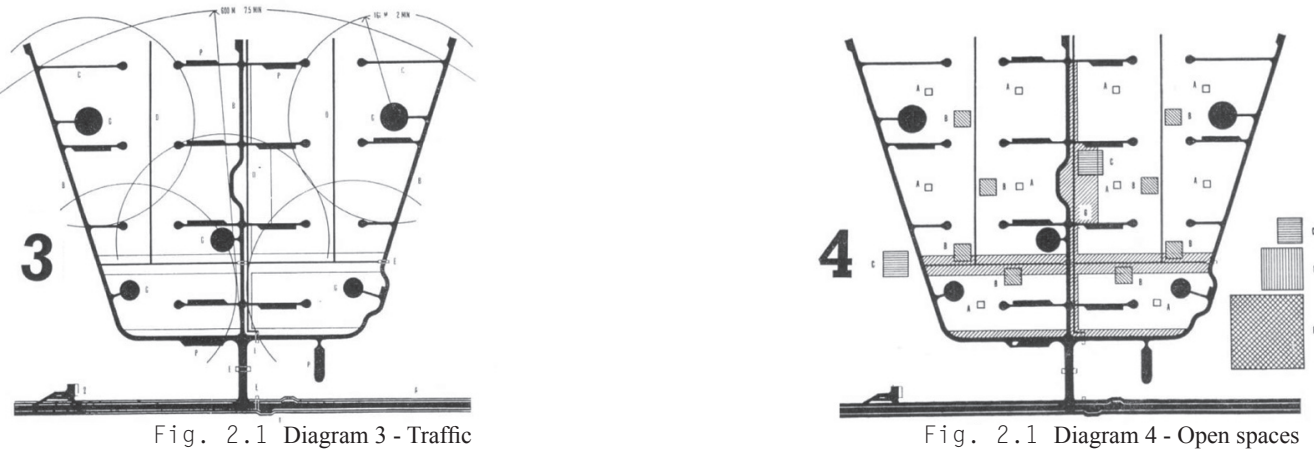
were adapted into storages. Following NATO air strikes in 1999, it was demonstrated that this system of defense had lost its basic purpose and so by renting the space the block shelters granted their position to the private interests. Today, they are the private gyms or local clubs or specialized shops from which both the private entrepreneurs and the city (Public Company for the Shelters Belgrade) collect the profit, but not the community.

Socially responsible local governance would comprise that each of this common spaces ensure the reciprocity of the private and the common interest. For this reciprocity a form of micro-regulation is needed. Microregulation ${ }^{7}$ provides functioning of the individual arrangements for the benefit of the neighborhood.

After the review of the dwelling community concept and the analysis of the diagrams which establish its territoriality the adaptability of this system to new conditions can be elaborated. On the basis of the system characteristics analysis ${ }^{8}$, I will present the general recommendations for collective form re-conceptualization in New Belgrade which are related to: control of system/environment boundaries, selectivity of the system and system being auto-referential.

General principles for the Re-conceptualization of the Collective Form in New Belgrade

The principle of reciprocity defines the duties towards the neighbor for the purpose of one's own sustain. This principle determines the principles for neighborhood territoriality establishment. Having in mind that the group form can develop into a system, the general recommendations for reconceptualization of the idea of neighborhood in New Belgrade are related to the territorial determinants of the system such as: Generative element of
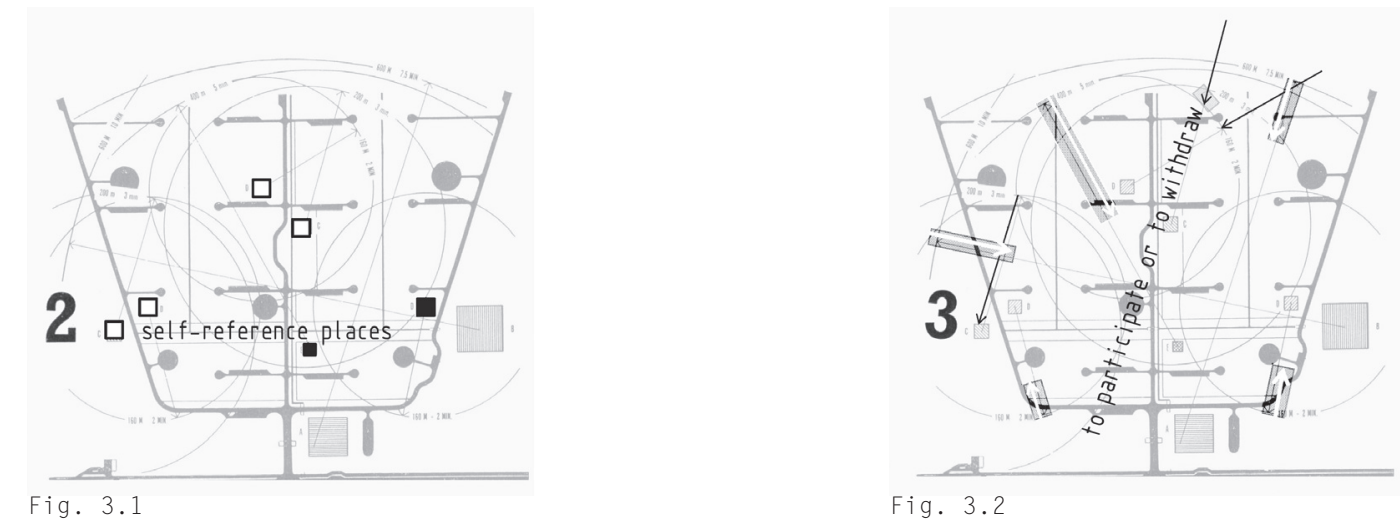
group form (prototype), Group form junctions (distances as functional orientation of the system elements), Group form boundaries (differentiation of conditions inside and outside the system).

The first principle for re-conceptualization of the idea of neighborhood in New Belgrade relates to the manner of establishing the group form by identifying its generic elements and re-defining the relations among them. As they are not autonomous entities, they are in reciprocal relation with their environment and they form a network. In the times of rapid changes, in inconsistent conditions, the network concept represents a rather adaptable, but also sustainable system. The network adapts itself to the changed circumstances, but retains the properties of the system it supports. For Shadrach Woods, the network is a manner of establishing the higher order system which by its nature enables the individual expression at higher level (Woods 1961, in Petrovic 2009:385). Therefore the first principle is related to flexibility of the group form:

If New Belgrade is no longer the representation of coherent, compact collective form, then it is a network of self-reference places. (Figure 3.1)

After the generic elements have been identified, it is necessary to reconsider their interaction. The second principle relates to the connections and use of common spaces, namely, that the individual elements do not figure as separate and self-sufficient entities but contribute one to another so that the distance between them, i.e. the nearness does not affect the closeness.

The system of common spaces functions as a system of group form junctions. In the dwelling community concept the system of common spaces has been designed as the stay in the community. Nowadays the leisure time is not harmonized with others so everyone can choose where and how to organize his/her-own relief, so the design of those places should achieved variation of places from the exposed outside to the intimate zones inside the dwelling.
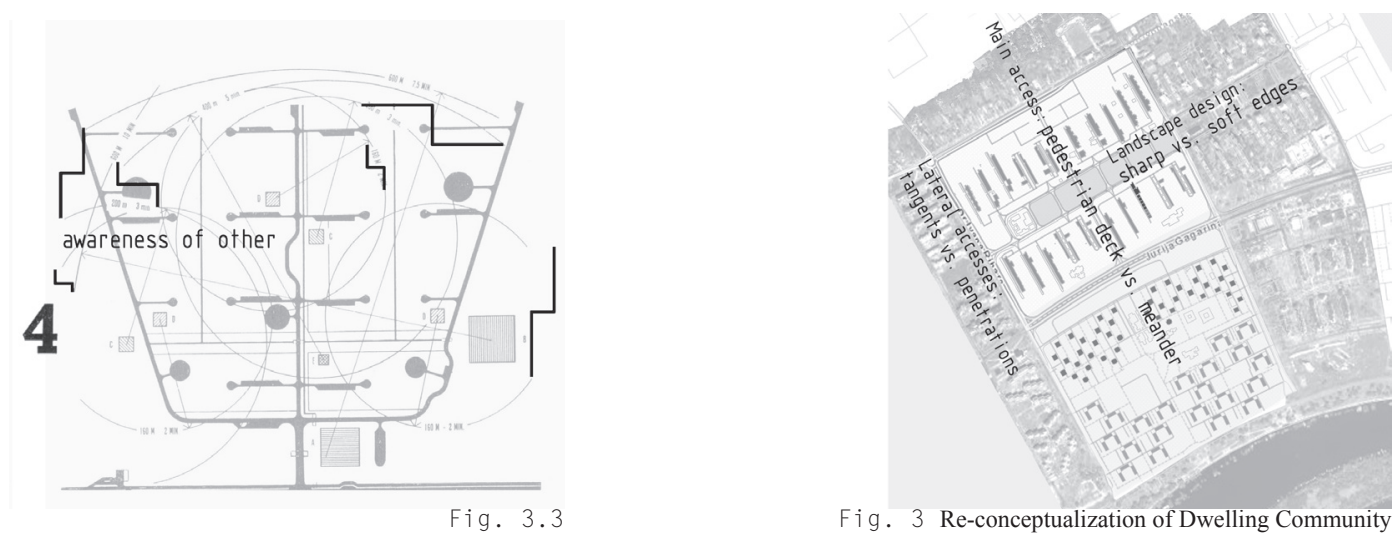
The second principle of re-conceptualization of the idea of neighborhood in New Belgrade relates to the way of common spaces organizing and arranging, namely to character nuance - from the high degree of exposure to the pronounced sheltered condition. Thereby in group form diverse degrees of interaction are achieved: 1 - intensive interaction; 2 - occasional cooperation; 3 - moderate cooperation; and 4 - mediated interaction. The network transfers the interaction. Group form interaction depends on connectivity of its junctions. It is necessary to re-define the connections between the dwelling units and the space such as shelters, shops, local service, child day-cares, kindergartens, schools and local communities' centers. These junctions have originally been established as the relation of served-servicing, nowadays it is desirable to establish the relation of reciprocity. The reciprocity means that each of the identified positions acquires attractive content (considering market conditions), but for the benefit of the neighborhood. This reciprocity reflects on the standard of living and expresses though the quality of place. ${ }^{9}$ Therefore, the second principle is:

Design junctions of the group form in a way that enables each citizen to be free to participate, and to withdraw (Figure 3.2).

The most sensitive issue of collective form transformation is its boundary. This buffer zone used to represent a distinct boundary determination of dwelling community territory and the environment. In dwelling community, the residential towers, rows and individual houses establish the differences within the system, so that the principle of their spreading, confirms the boundary within the system and suggests diverse themes for design of access to the group form. The first transformations ${ }^{10}$ which occurred at the junctions and along the major traffic routes, in the zone of entrance into the dwelling community, testify to the sensitivity of the block boundaries issue.

The standpoint which is against the fences and solid boundaries in the area of New Belgrade residential area is in line with the initial concept of dwelling community as a 'flexible organism'. Design of group form boundaries is required for establishing the contacts of diverse intensity and character between the system and the environment. In group form of moderate cooperation the contact and division exist as distinct or hidden, depending on the position in group form. It is desirable that the structures emerging at the block boundary respect the pedestrian routes and diversification of conditions within the territory. For the projects of transformation of the dwelling community boundaries in New Belgrade, in the sample of the Sava local community and the Kozara local community, three key positions and themes have been identified: 1 - Main access (corridor vs. meander) 2 - Landscape design of 
inner junctions (sharp vs. soft edges) and 3 - lateral accesses (tangents vs. penetrations). Thus, the third principle would be:

Instead of enclosed or integrated space - awareness of activities outside, informally coordinated and synchronized one with another (Figure 3.3).

For further work on reconceptualization of the idea of neighborhood in postsocialist city it is necessary to discuss the adequacy of the following terms for the diverse neighborhood patterns: 1 - group form of intensive interaction; 2 group form of occasional cooperation; 3 - group form of moderate cooperation and 4 - group form of mediated interaction. These terms suggest that the neighborhood possesses the elements due to which it can develop into a system (thus a group form) and that this form is shaped by diversified interpersonal relations such as: solidarity (1), confidence (2), distrust (3), skepticism (4).

According to the principle of reciprocity, based on the criteria of functional orientation, attractiveness and connectivity of group form elements, considering the presence of the culture of distrust, those general recommendations reveal the key points for transformation of the dwelling community into group form of moderate cooperation. of Science of the Republic of Serbia, Mina Petrovic has researched the analytical concepts of the urban neighborhood studies and the meanings which the actors of the spatial practices attribute to the neighborhood. The results of this research was published in the paper: "Research of the social aspects of the urban neighborhood : Perception of the experts in New Belgrade". Petrovic, also, participated in the international project: " Differentiated Neighborhoods" organized by the Museum of Contemporary Art in Belgrade. of the Board of the Second International Magazines Exhibition" "Family and Household 1958". The Faculty of Architecture in Belgrade : Prof. M. Bajlon; Assistant: B. Aleksic, B. Milenkovic, D. Nastic; Designing Group of Atelier 4: Prof. arch. Djordje Krekic, arch. Branko Babic, arch. Zvonko Veber; Associates of the Atelier Dwelling community: Eng.arch. Maja Dobrovec, Eng. Arch. Vlado Sedej and undergraduate ABD students of architecture: T. Blejec, M. Gnamus, R. Sersa, B. Mikuz, V. Sekavnik, F. Cizek, D. Vala, Z. Verbic. Besides the architects the following 
organizations took part in preparation of this magazine: The Bureau of National Health, National Municipality of New Belgrade, Regional Center for Promotion of the Household and National Board Zrenjanin, Saraejvo and Zagreb, Town Planning Bureau Zagreb, Sarajevo, Bureau of Social Policy of the National Republic of Serbia.

This is in conformity with the socialist ideology which does not support individualism.

The social capital domains, according to Forrest and Kearns, at the level of neighborhood comprises: enlarge of power, participation, associative activities and common goals, networks of support and reciprocity, standards and values, confidence, security, identity (Forrest and Kearns, 2001: 2140, from Petrovic, 2007)

The proposed micro-regulation is a system of spatial and social distancing which is determined by the neighbors with the architects, That is a set of rights and obligations which the neighbors have in respect to the space in neighborhood, and not in respect to the municipality or the individuals as specified by the dwelling community by-law. This set of rules is contained in the neighborhood plan.

Luhmann states twelve aspects of system analysis: 1- difference between system and environment; 2-differentiatio as a unity, as a unitas multiplex; 3-why and how causality is distributed over system and environment; 4- difference between element and relation; 5- conditioning; 6- complexity; 7- function of system boundaries; 8- adaptation; 9- self-reference; 10- conversation or multiple constitution; 11- system processes; 12- the principle of extension.( Luhmann, N. Social Systems. Stanford California: Stanford University Press, 1995. pp.16-41.)

The notion "quality of place' was introduced by Richard Florida in order to emphasize three essential dimension of creative class residential preferences: that which is present there ( refers to the combination of the morphology and natural environment), who is present there ( what type of people live in the neighborhood and who visits them) and what happens there ( the diversity of possible activities, to which extent and on the basis of which activities the neighborhood is attractive) (in Petrovic, 2007)

Kiosks and individual shops are located by the public transportation stops. Later on there came to more pronounced and permanent change such as markets, shopping malls, and thereafter also the residential-business entities of traditional construction and most often they present the barrier at the entrance into the block. 1958. (Ljubljana) Progres:1958.

Figure 1.1 Dwelling Community Concept in New Belgrade (M.M.)

Figure 1.2 Dwelling Community - Settlement Growth Unit (Progres, 1958)

Figure 2 .

2.1 Diagram 1 - Disposition of physical form, (Progres, 1958)

2.2 Diagram 2 - Service areas and centres, (Progres, 1958)

2.3 Diagram 3 - Traffic, (Progres, 1958)

2.4 Diagram 4 - Open spaces, (Progres, 1958)

Figure 3

$3.1-3.3$ Re-conceptualization of Dwelling Community (M.M) 
Gaković, Stanko. Sveska 3: Četiri stanja sklopa u strukturi stambene sredine. Beograd: Arhitektonski fakultete Univerziteta u Beogradu, 1991.

Hobbes, Thomas. Man and Citizen (De Hommine and De Cive). Indianopolis: Hacket Publishing Company, 1991.

Luhmann, Niklas. Social Systems (1984). Translated by John Bednarz, Jr. with Dirk Beacker. Stanford, California: Stanford Univesity Press, 1995.

Макsimović, Branko. Urbanizam u Srbiji, osnovna ispitivanja $i$ dokumentacija,. Beograd: Izdavačka kuća Koste J. Mihajlovića, 1938.

Milić, A. Vladimir. Urbanistički aspekti socijalnog stanovanja. Beograd: Arhitektonski fakultet Univerziteta u Beogradu, 2006.

Newman, Oscar. Defensible Space - Crime Prevention Through Urban Design (1973). New York: Macmillan Publishing Co., Inc, 1973.

Perović, Miloš. Antologija Teorija arhitekture XX veka. Beograd: Građevinska knjiga, 2009.

Petrović, Mina. Researching Social Aspects of Urban Neighborhood: Reflections of Proffesionals in New Belgrade. Sociology (L No 1/2008)

Robinson, Julia W. Institution and Home: Architecture as a Cultural Medium. Transformation 7. Amsterdam: Techne Press, 2006.

Sack, Robert David. Human Territoriality: Its Theory and History. Cambridge: Cambridge University Press, 1986.

Smithson Alison / Smithson Peter, "Building Toward the Community Structure" Gyorgy Kepes, ed., Structure in Art and in Science (London: Studio Vista, 1965), pp. 111-115. 